\title{
Myoepithelial markers are expressed in at least $29 \%$ of oestrogen receptor negative invasive breast carcinoma
}

\author{
Rachel Kesse-Adu and Sami Shousha \\ Department of Histopathology, Charing Cross Hospital and Faculty of Medicine, Imperial College, \\ London, UK
}

\begin{abstract}
Around $20 \%$ of invasive breast carcinoma are oestrogen receptor alpha (ER) negative. Theoretically, this negativity could be either due to the result of downregulation of ER expression in the tumour cells, or the result of the tumour being derived from or differentiating towards cells which normally lack that expression. Normal basal, including myoepithelial, cells of the breast are ERnegative. CD10, smooth muscle actin and S100 are markers of these basal cells that can be used for their demonstration in routinely processed sections. This study was aimed at comparing the incidence of positivity for three myoepithelial markers in ER-negative and ER-positive invasive breast carcinoma. We have examined sections of 117 cases of breast carcinoma, including 77 ER-negative and 40 ER-positive cases, for the expression of CD10, smooth muscle actin and S100, using the avidin-biotin complex immunoperoxidase technique. A tumour was considered positive if more than $10 \%$ of the tumour cells were positively stained. In all, 36 (47\%) ER-negative tumours were positive for one or more of these myoepithelial markers. The percentage of positively stained tumour cells varied between 30 and $100 \%$. Of the 40 ER-positive tumours, only three (8\%) were positive; two for $\mathbf{S 1 0 0}$ and one for actin, with none being positive for CD10. If cases stained only with $\mathrm{S} 100$ are excluded, as some of these may represent luminal differentiation, definite myoepithelial differentiation seems to be present in $29 \%(22 / 77)$ of ER-negative tumours as compared with $2.5 \%(1 / 40)$ of ER-positive tumours; a difference which is highly significant $(P<0.001)$. It is suggested that at least $29 \%$ of ER-negative invasive breast carcinomas may be derived from or differentiating along the direction of basal nonconventional luminal epithelial breast cells that normally lack the expression of ER but totally or partially express various myoepithelial markers. Such tumours might need a different therapeutic approach.

Modern Pathology (2004) 17, 646-652, advance online publication, 9 April 2004; doi:10.1038/modpathol.3800103
\end{abstract}

Keywords: breast; breast carcinoma; ER; myoepithelial cells; CD10; S100; smooth muscle actin

Around $20 \%$ of invasive breast carcinoma are oestrogen receptor alpha (ER) negative. ${ }^{1-3}$ This ER negativity is not the result of mutations in the coding region of the ER gene. ${ }^{4}$ Thus, theoretically this negativity could be either the result of downregulation of ER expression in the tumour cells, or the result of the tumour being derived from cells which normally lack that expression. Normal basal, including myoepithelial, cells of the breast are ERnegative. ${ }^{5,6}$ CD10, $^{7,8}$ smooth muscle actin ${ }^{9,10}$ and $\mathrm{S}_{100^{11}}$ are markers of these basal cells that can be used for their demonstration in routinely processed

Correspondence: Dr S Shousha, MD, FRCPath, Department of Histopathology, Charing Cross Hospital, Fulham Palace Road, London W6 8 RF, UK.

E-mail: s.shousha@ic.ac.uk

Received 27 October 2003; revised 05 February 2004; accepted 16 February 2004; published online 9 April 2004 paraffin sections. Normal luminal breast epithelial cells are usually negative for these three markers. ${ }^{5-11}$ This study was aimed at comparing the incidence of positive staining for the above-mentioned three myoepithelial markers in ER-negative and -positive invasive breast carcinoma, to investigate the possibility that differentiation along myoepithelial lines plays a role in imparting ER negativity on some breast carcinomas.

\section{Materials and methods}

Sections of 117 selected cases of female invasive breast carcinomas were examined. These included 77 consecutive ER-negative and 40 consecutive ERpositive cases, as assessed immunohistochemically (see below). For each case, all archival haemotoxylin and eosin-stained sections were reviewed concerning the histological type and tumour grade. The 
Table 1 Antibodies used

\begin{tabular}{llcl}
\hline Antibody & Clone & Concentration & Source \\
\hline CD10 & NCL-CD10- & $1: 80$ & $\begin{array}{l}\text { Novacastra, } \\
\text { Newcastle, UK }\end{array}$ \\
Smooth & A-2547 & $1: 8000$ & $\begin{array}{l}\text { Sigma, USA } \\
\text { muscle actin }\end{array}$ \\
S100 & NCL-S100p & $1: 1000$ & $\begin{array}{l}\text { Novacastra, } \\
\text { Newcastle, UK }\end{array}$ \\
& & &
\end{tabular}

latter was assessed using Elston and Ellis's criteria. ${ }^{12}$ Tumour size and axillary lymph node status, when available, were obtained from the patient's histological report. Sections stained for ER, which is carried out routinely in our department, were also reviewed to confirm the receptor status of the tumour. New sections were then cut from the paraffin block corresponding to a representative section of the tumour, for the immunohistochemical tests done for this study.

For ER assessment, we use the avidin-biotin complex immunoperoxidase (ABC) technique and the monoclonal antibody 1D5 (Dako Ltd, Cambridgshire, UK) in a concentration of 1:100. An antigen retrieval step, using a pressure cooker, is carried out before applying the primary antibody. ${ }^{13}$ All ERnegative cases selected for this study were completely devoid of any positive nuclear staining of tumour cells. ER-positive cases had at least 10\% positively stained tumour cells, with the majority having $100 \%$ positive nuclear staining.

The ABC technique was also used for the demonstration of the three myoepithelial markers CD10, smooth muscle actin and S100. The antibodies used, their concentrations and source are shown in Table 1. CD10 was demonstrated after an antigen retrieval step using a pressure cooker. No antigen retrieval step was used for the other two antibodies. A tumour was considered positive if more than $10 \%$ of the tumour cells were positively stained.

Statistical analysis was carried out using the T and $\chi^{2}$-tests.

\section{Results}

The 77 patients with ER-negative tumours varied in age between 29 and 84 years with a mean age of 56.2 $( \pm 14.93)$ years. For the 40 patients with ER-positive tumours, the ages varied between 31 and 90 years with a mean of $58.8( \pm 15.81)$ years, respectively. The difference in age between the two groups is not significant $(P=0.3695$, Table 2$)$. The ER-negative tumours varied in size between 2 and $130 \mathrm{~mm}$ with a mean of $25.3 \mathrm{~mm}( \pm 21.67)$, while the ER-positive lesions had a size range of $8-50 \mathrm{~mm}$ with a mean of $17.7( \pm 8.62) \mathrm{mm}$, the difference is statistically significant $(P=0.008$, Table 2$)$.
Table 2 Patients and tumour characteristics

\begin{tabular}{lccc}
\hline & $\begin{array}{c}\text { ER negative } \\
(\mathrm{n}=77)\end{array}$ & $\begin{array}{c}\text { ER positive } \\
(\mathrm{n}=40)\end{array}$ & $\mathrm{P}$ \\
\hline $\begin{array}{l}\text { Mean age } \\
\text { (years) }\end{array}$ & 56.2 & 58.8 & 0.3695 \\
$\begin{array}{l}\text { Tumour size } \\
\text { (mm) }\end{array}$ & 25.3 & 17.7 & $0.008^{*}$ \\
$\begin{array}{l}\text { Grade 3 } \\
\text { tumours }\end{array}$ & $63(82 \%)$ & $4(10 \%)$ & $<0.001^{*}$ \\
$\begin{array}{l}\text { Node } \\
\text { metastasis }\end{array}$ & $36 / 65(55 \%)$ & $9 / 28(32 \%)$ & $<0.05^{*}$ \\
\hline
\end{tabular}

*Difference statistically significant.

The great majority of the tumours in the two groups were of the invasive ductal type (94\% (72/ 77) of ER-negative, and 88\% (35/40) of ER-positive ones). The remaining tumours were of histological special types. In the ER-negative group these included 3 medullary/atypical medullary, one invasive apocrine and one adenoid cystic carcinoma. The special types in the ER-positive group included four invasive lobular and one tubular/cribriform. On the other hand, the ER-negative tumours included a significantly higher percentage of grade 3 lesions. Thus, of the 77 ER-negative tumours, $63(82 \%)$ were grade $3,13(17 \%)$ grade 2 and only one $(1 \%)$, the adenoid cystic carcinoma, was grade 1 . For the 40 ER-positive tumours, only four $(10 \%)$ were grade 3 , $25(62 \%)$ grade 2 and $11(28 \%)$ were grade 1 $(P<0.001$, Table 2).

Information about axillary lymph node status was available for 65 patients with ER-negative tumours and 28 with ER-positive tumours. The number of lymph nodes examined in these cases varied between four and 42. Axillary lymph node metastases were present in $55 \%$ (36/65) of patients with ER-negative tumours, compared with $32 \%(9 / 28)$ of those with ER-positive lesions. The difference is statistically significant $(P=<0.05$, Table 2$)$.

\section{CD10}

CD10 positivity was indicated by dark-brown cell membrane and cytoplasmic staining. Myoepithelial cells in normal ducts and acini, as well as in benign cysts, were CD10 strongly positive (Figure 1a). Luminal epithelial cells were negative. In all, 12 out of $77(16 \%)$ ER-negative tumours were CD10 positive (Figure 2). The percentage of positively stained tumour cells varied between 30 and $100 \%$. One more ER-negative tumour showed CD10 expression in $10 \%$ of tumour cells but this was considered negative. None of the 40 ER-positive tumours was considered CD10 positive, as the percentage of stained tumour cells in the only case that showed such a staining did not exceed $10 \%$. The difference between the staining in the two groups is statistically significant $(P<0.01)$. 

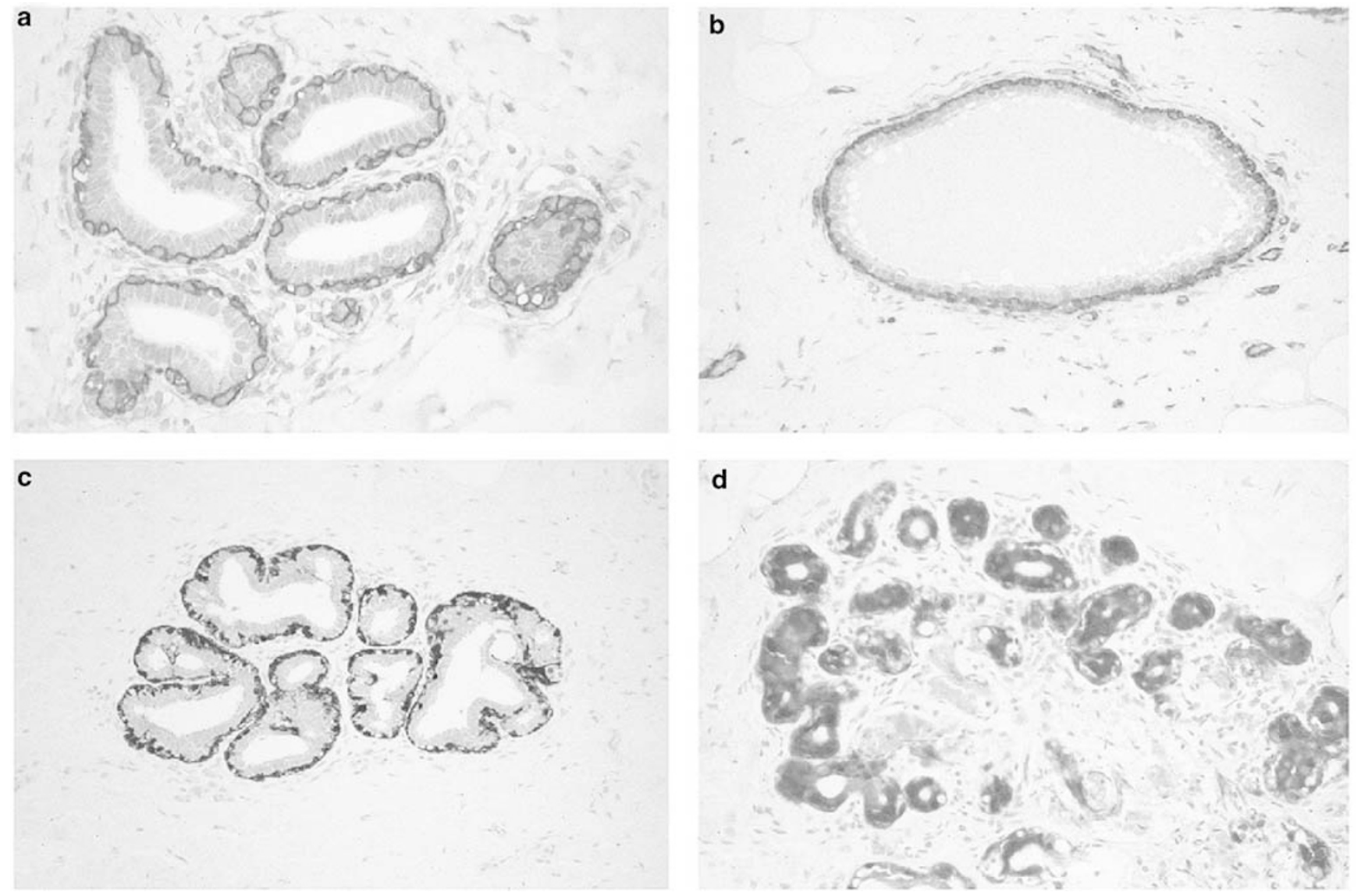

Figure 1 Myoepithelial cells in normal breast ducts stained with: (a) CD10, (b) Smooth muscle actin, and (c) S100. (d) A group of normal acini showing positive S100 staining of luminal epithelial cells. Immunoperoxidase.

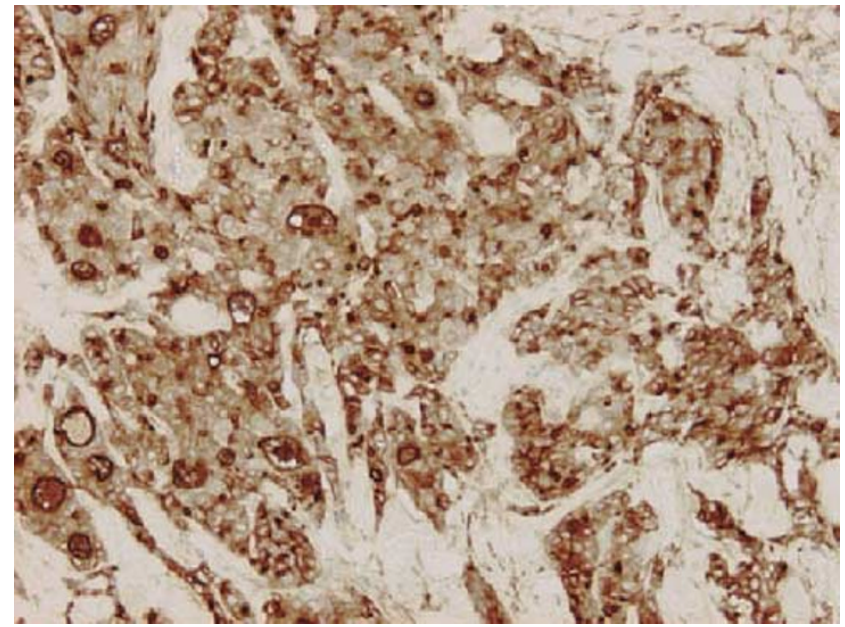

Figure 2 CD10-positive invasive ductal carcinoma, almost all the tumour cells are positively stained. This case was smooth muscle actin and S100 negative. Immunoperoxidase.

CD10-positive stromal staining was sometimes seen in negative and positive tumours, but not in normal breast stroma.

The 12 CD10-positive tumours included 11 invasive ductal (nine grade 3 and two grade 2) and one atypical medullary carcinoma. The patients varied in age between 37 and 84 years, and the tumours varied between 15 and $30 \mathrm{~mm}$ in maximum dimension. Axillary lymph node metastases were present in nine out of 11 patients (82\%) on whom axillary dissection was carried out. CD10 was not detected in any of the four invasive lobular carcinomas examined nor in the single cases of invasive apocrine, adenoid cystic or tubular/cribriform tumours. None of the 12 CD10-positive cases expressed smooth muscle actin, but four expressed S100.

\section{Smooth Muscle Actin}

Positivity was indicated by dark-brown cytoplasmic staining. Myoepithelial cells surrounding normal ducts and acini and cysts were positively stained as well as the walls of blood vessels. Normal luminal epithelial cells were negative (Figure 1b).

In all, 11 tumours showed positive staining in more than $10 \%$ of the tumour cells. These included 10 out of 77 (13\%) ER-negative and one out of 40 (3\%) ER-positive cases; the difference is not statistically significant $(P<0.1)$. All 11 actin-positive cases were CD10 negative, but eight $(73 \%)$ were S100 positive. The patients with actin-positive tumours varied in age between 33 and 70 years, 


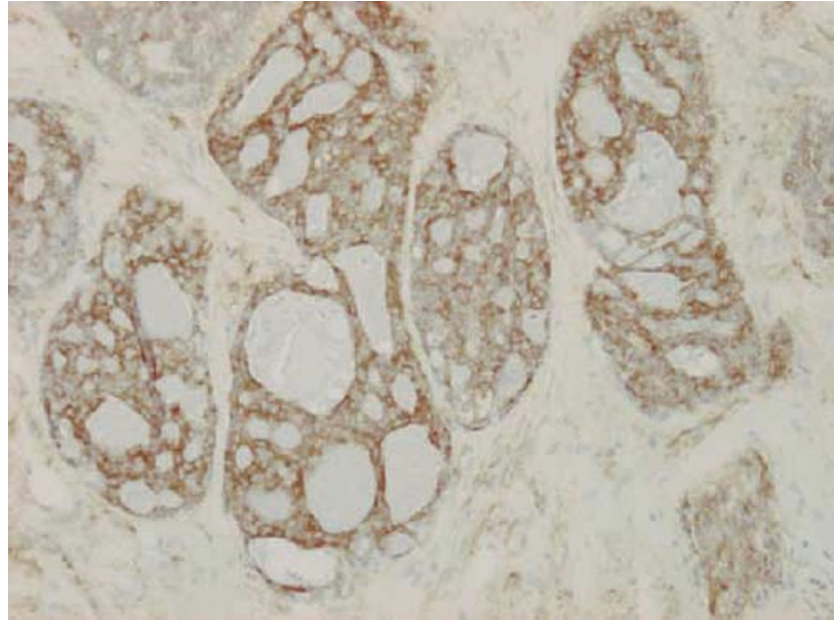

Figure 3 Adenoid cystic carcinoma showing positive staining with smooth muscle actin. This tumour was CD10 and S100 negative. Immunoperoxidase.

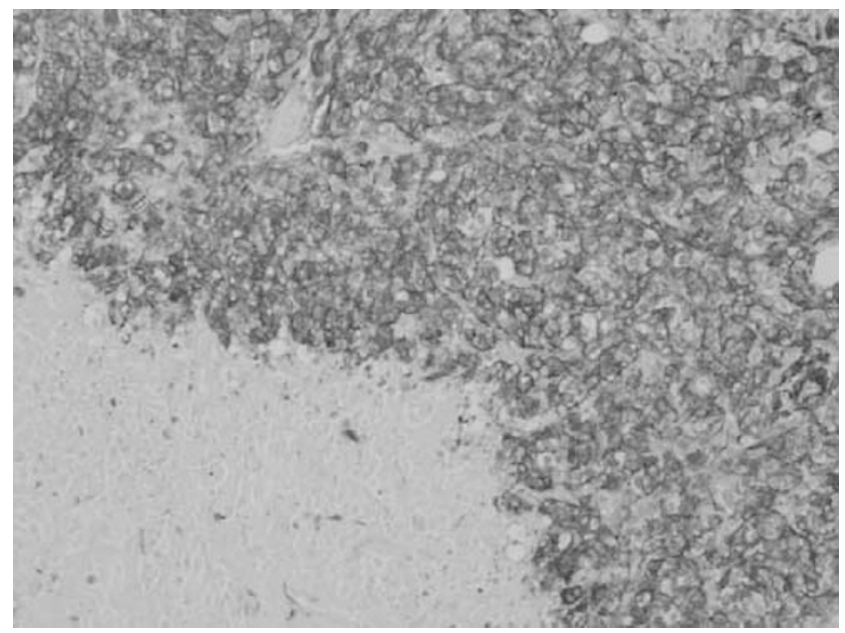

Figure 4 Invasive ductal carcinoma with large central scar (ring carcinoma) showing strong positive staining with smooth muscle actin. This tumour was S100 positive and CD10 negative. Immunoperoxidase.

and the tumours varied in size between 10 and $32 \mathrm{~mm}$. Axillary node metastases were present in three out of eight patients (38\%), on whom axillary dissection was carried out. In all, 10 of the actinpositive tumours were invasive ductal (nine grade 3 and one grade 2) and one was adenoid cystic (Figure 3 ). The most extensive staining, almost $100 \%$ of tumour cells, was seen in the only case of a grade 3 invasive ductal carcinoma with large central scar (ring carcinoma), ${ }^{3}$ included in this study (Figure 4).

\section{S100}

Positivity was indicated by dark-brown cytoplasmic and sometimes nuclear staining. Most myoepithelial cells around normal ducts and acini were positively stained, while normal luminal epithelial cells were
Table 3 Summary of the overall staining

\begin{tabular}{lcc}
\hline Marker & ER negative $(\mathrm{n}=77)$ & ER positive $(\mathrm{n}=40)$ \\
\hline CD10 & 8 & 0 \\
CD10 + S100 & 4 & 0 \\
Actin & 2 & 1 \\
Actin + S100 & 8 & 0 \\
S100 & 14 & 2 \\
Total & $36(47 \%)^{*}$ & $3(8 \%)^{*}$ \\
\hline
\end{tabular}

${ }^{*} P<0.001$

mostly negative (Figure 1c). Occasional groups of normal-looking acini with positively stained epithelial cells were seen in some cases (Figure 1d), and normal ducts with negatively stained myoepithelial cells were sometimes seen.

S100 positivity was seen in 28 tumours including 26 out of 77 (34\%) ER-negative and two out of 40 (5\%) ER-positive cases; the difference is statistically significant $(P<0.001)$. The patients with S100positive tumours varied in age between 33 and 70 years and the tumours varied in size between 10 and $52 \mathrm{~mm}$. Metastatic carcinoma was present in the axillary lymph nodes in 14 out of the 25 (64\%) patients in whom axillary dissection was carried out. In all 26 of the tumours were invasive ductal (23 grade 3 , two grade 2 and one grade 1 ), and two were medullary/atypical medullary. Four of the 28 tumours (14\%) were CD10-positive and eight (29\%) were smooth muscle actin positive, including the ring carcinoma.

\section{Overall Expression of the Three Markers}

Expression of one or more myoepithelial marker was seen in 36 out of 77 (47\%) ER-negative tumours, and in three out of 40 (8\%) ER-positive tumours (Table 3). The difference between the expression in the two tumour types is highly significant $(P<0.001)$. Only one myoepithelial marker was expressed in 24 ERnegative and three ER-positive tumours. Two markers were expressed in 12 ER-negative and in none of the ER-positive tumours. No individual tumours in this study expressed all the three myoepithelial markers tested.

\section{Discussion}

Two main findings come out of this study. First, there is a high incidence of myoepithelial markers' expression in ER-negative compared with ER-positive tumours. Second, there is a divergence of expression of the three myoepithelial markers employed in this study in individual tumours.

Of the three markers used, S100 was the most frequently detected, although the staining was usually focal and its intensity variable. In all, 28 out of the 117 tumours examined (24\%) showed 
positive staining in more than $10 \%$ of the tumour cells. This percentage is lower than the $44-84 \%$ previously reported..$^{14-16}$ The difference is probably related to our use of a cut-off point of $10 \%$ positive tumour cells before considering a case being positive; a threshold which was not used in the other studies. In our view, using this cutoff point is useful, as the presence of a few scattered positive cells was not unusual, and a cutoff point is commonly used when interpreting most immunohistochemical results of breast carcinoma. On using this threshold, the great majority of S100-positive breast carcinomas were ER negative (26 out of 28, $93 \%)$. However, only 12 of the 28 tumours (43\%) also stained with one of the other two myoepithelial markers used (eight with actin and four with CD10). This together with the fact that S100 has been seen in this, and other ${ }^{14,16}$ studies to occasionally stain luminal epithelia cells, suggest that some of these cases, especially those with no simultaneous actin or CD10 staining, may be exhibiting a particular luminal, rather than myoeithelial, cell differentiation. As the majority of these tumours were ER negative, it is possible that this 'particular' luminal differentiation is devoid of ER expression. The absence of S100 staining in eight CD10-positive and three actin-positive cases, probably reflects the fact, which was also noted in this and other studies, ${ }^{16}$ that not all myoepithelial cells stain positively with S100.

The number of cases staining for CD10 and smooth muscle actin was more limited, but these are the most likely cases with more definite myoepithelial differentiation. Neither CD10 $0^{7,8}$ nor smooth muscle actin ${ }^{9,10}$ has been shown previously, or in this study, to stain luminal epithelial cells. If the cases positive with these two antibodies are considered together, this would mean that 22 out of the 77 ER-negative tumours $(29 \%)$ showed strong evidence of myoepithelial differentiation, and 10 of these 22 were also positive for S100. In contrast, only one ER-positive case, out of $40(2.5 \%)$ was stained for actin, and none stained for CD10; a difference which is clearly highly significant $(P<0.001)$. This would lead us to suggest that around a third of ER negative invasive breast carcinomas could possibly be ER negative because they are derived from cells differentiating along myoepithelial lines.

Until recently, myoepithelial cells of the breast were thought to be rather inert with no active role in neoplasia. It is now accepted that myoepithelial cells can be involved in a variety of breast neoplasms. The best recognised are the myoepitheliomas and adenomyoepitheliomas, but there are a few others. Myoepitheliomas (myoepithelial carcinomas) are thought to be extremely rare malignant tumours composed entirely of neoplastic myoepithelial cells which can be spindle shaped ${ }^{17-19}$ or clear, ${ }^{20,21}$ and stain positively for cytokeratin, smooth muscle actin ${ }^{20}$ and S100 ${ }^{18,20,21}$ and are ER- and PgR negative. ${ }^{17}$ A more recent molecular study of 10 cases from British and Italian patients demonstrated genetic alterations involving chromosomes 11,16 and $17 .^{22}$

Adenomyoepitheliomas are relatively more common neoplasms that consist of two distinct epithelial and myoepithelial elements. ${ }^{18,23,24}$ These lesions are mostly benign and three patterns have been described: spindle cell, tubular and lobulated. ${ }^{18} \mathrm{~A}$ combination of patterns may coexist in the same lesion, and the epithelial elements may undergo metaplastic changes including apocrine, mucinous, squamous or sebaceous. ${ }^{18}$ Immunohstochemically, both epithelial and myoepithelial elements are keratin positive, with the latter elements also positive for smooth muscle actin and $S 100 .^{25,26}$ Malignant change may occur within these lesions. ${ }^{18,27-29}$

Adenoid cystic carcinoma a third tumour that can occur in the breast, is thought to be derived from myoepithelial cells, and is usually smooth muscle actin and S100-positive and ER negative. ${ }^{30}$ There has also been another two distinct tumour types described in the literature with myoepithelial differentiation: one described as a poorly differentiated myoepithelial cell-rich carcinoma, ${ }^{31}$ and the other as high-grade invasive ductal carcinoma with large central acellular zones with myoepithelial differentiation. ${ }^{32}$ We have found out that the latter tumour is usually ER negative. ${ }^{3}$

We suggest that the above list of myoepithelialrelated breast neoplasms is not inclusive, and that there are probably other invasive breast carcinomas that are currently included within the group of 'invasive ductal, not otherwise specified' which are ER negative and show immunohistochemical evidence of myoepithelial, or other basal cell differentiation. Such tumours may be worth identifying separately as they probably need a different therapeutic approach. The 'high-grade ductal carcinoma with extensive central scar' (ring carcinoma), may be one of these lesions that is becoming gradually more defined morphologically and clinically,,32-34 in spite of the absence of an agreed name. Further analysis of more cases may lead to the identification of other distinct subtypes. One of these potential subtypes could be the grade 3 invasive ductal carcinoma with extensive comedo necrosis (invasive comedo carcinoma), which we have previously noted to be always ER negative. ${ }^{3}$ In the current study, we had four of such cases, all were CD10 negative, but two were S100 positive and one was smooth muscle actin positive (Figure 5).

It has to be added here that we only had a few cases in which the total neoplastic population within the tumour stained positively with one or more of the myoepithelial markers (Figures 2 and 3 ). In the majority of cases, there was a mixture of positive and negative cells as previously explained. This would support the emerging evidence of the existence of a bipotent mammary progenitor or stem 


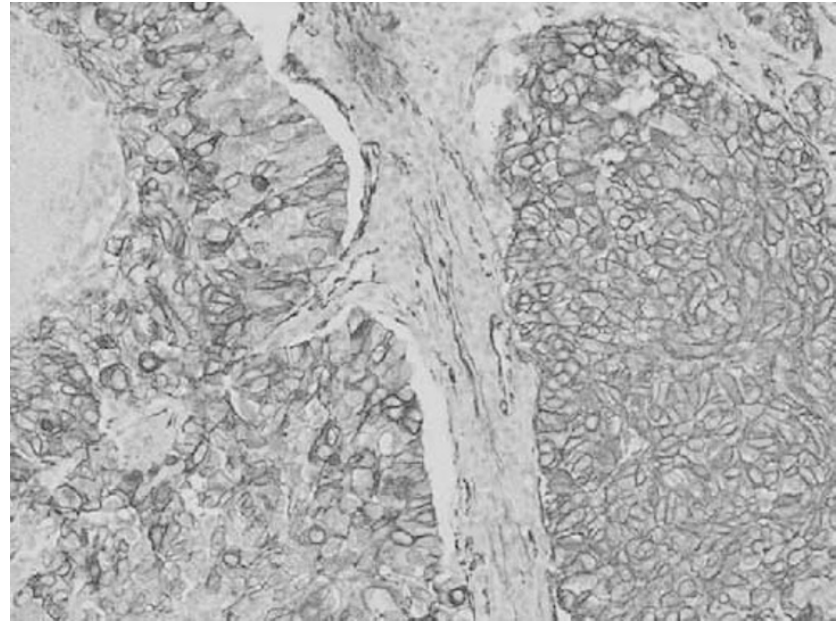

Figure 5 Invasive ductal carcinoma with extensive comedo necrosis (invasive comedo carcinoma) showing strong positive staining with smooth muscle actin. This tumour was CD10 negative, but S100 positive. Immunoperoxidase.

cell capable of differentiating along luminal and myoepithelial lines. ${ }^{35,36}$ If this is the case, it is interesting that both of these elements in the great majority of the cases examined in this study (36/39, $92 \%$ ) were ER negative.

Another point of interest which is difficult to explain is the dichotomy of CD10 and smooth muscle actin expression in the tumours studied. Both markers were uniformly present in normal myoepithelial cells, but we have not seen any individual cases of carcinomas that stain with both markers. The proteins identified by the two markers are probably different, and it seems that although they are both present in normal cells, they become exclusively separated with malignant transformation. This suggests the presence of more than one pathway for such transformation and the presence of more than one type of transformed neoplastic myoepithelial/basal cells. This is further supported by the variety of staining combinations noted in the studied tumours with the three markers (Table 3). This dichotomy of expression was also noted, to some extent, in stromal myofibroblasts, which tended to be more commonly and extensively stained with smooth muscle actin rather than CD10, although positive staining with the latter was noted in several cases in this as well as in other studies. ${ }^{8,37}$ In this respect, recent studies have suggested the existence of more than one type of myofibroblasts in breast lesions, which vary in their expression of smooth muscle actin and CD34. ${ }^{38}$ It has to be added here, that it would be interesting to compare the staining results of the recently introduced nuclear myoepithelial cell marker $\mathrm{p} 63^{39}$ with the more established cytoplasmic markers for these cells in a future study.

Our study also shows that the incidence of lymph node metastasis was highest in patients with CD10positive tumours $(9 / 11 ; 82 \%)$, followed by those with S100-positive lesions $(14 / 25 ; 64 \%)$ and lowest in those with tumours expressing smooth muscle actin $(3 / 8 ; 38 \%)$. More cases have to be examined and clinical follow-up analysed before making definite conclusions about the apparent high aggressiveness of CD10-positive breast carcinomas.

It is concluded that at least $29 \%$, and possibly up to $47 \%$, of ER-negative invasive breast carcinomas may be derived from or show differentiation in the direction of basal nonluminal epithelial mammary cells that normally lack the expression of ER but express CD10, smooth muscle actin or S100. Such tumours might need a different, more specific therapeutic approach.

\section{Acknowledgement}

This work was submitted in partial fulfilment of BSc degree requirement (for RK-A).

\section{References}

1 Rhodes A, Jasani B, Balaton AJ, et al. Frequency of oestrogen and progesterone receptor positivity by immunohistochemical analysis in 7016 breast carcinomas: correlation with patient age, assay sensitivity, threshold value, and mammographic screening. J Clin Pathol 2000;53:688-696.

2 Zafrani B, Hubriot M-H, Mouret E, et al. High sensitivity and specificity of immunohistochemistry for the detection of hormone receptors in breast carcinomas: comparison with biochemical determination in a prospective study of 793 cases. Histopathology 2000;37:536-545.

3 Scawn R, Shousha S. Morphologic spectrum of estrogen receptor-negative breast carcinoma. Arch Pathol Lab Med 2002;126:325-330.

4 Roodi N, Bailey LR, Kao W-Y, et al. Estrogen receptor gene analysis in estrogen receptor-positive and receptor-negative primary breast cancer. J Natl Cancer Inst 1995;87:446-451.

5 Boyd MT, Hildebrandt RH, Bartow SA. Expression of the estrogen receptor gene in developing and adult human breast. Breast Cancer Res Treat 1996;37:243251.

6 Russo J, Ao X, Grill C, et al. Pattern of distribution of cells positive for estrogen receptor $\alpha$ and progesterone receptor in relation to proliferating cells in the mammary gland. Breast Cancer Res Treat 1999;53:217-227.

7 Chu P, Arber DA. Paraffin-section detection of CD10 in 505 nonhematopoietic neoplasms. Frequent expression in renal cell carcinoma and endometrial stromal sarcoma. J Clin Pathol 2000;113:374-382.

8 Moritani S, Kushima R, Sugihara H, et al. Availability of CD10 immunohistochemistry as a marker of breast myoepithelial cells on paraffin sections. Mod Pathol 2002;15:397-405.

9 Gugliotta P, Sapino A, Macri L, et al. Specific demonstration of myoepithelial cells by anti-alpha smooth muscle actin antibody. J Histochem Cytochem 1988;36:659-663. 
10 Lazard D, Sastre X, Frid MG, et al. Expression of smooth muscle-specific proteins in myoepithelium and stromal myofibroblasts of normal and malignant human breast tissue. Proc Natl Acad Sci USA 1993;90:999-1003.

11 Kahn HJ, Marks A, Thom H, et al. Role of antibody to S100 protein in diagnostic pathology. Am J Clin Pathol 1983;79:341-347.

12 Elston CW, Ellis IO. Pathological prognostic factors in breast cancer. I. The value of histological grade in breast cancer: experience from a large study with longterm follow up. Histopathology 1991;19:403-410.

13 Shousha S, Peston D. Immunohistochemical demonstration of oestrogen and progesterone receptors in paraffin sections of breast carcinoma. Curr Diag Pathol 1997;4:176-180.

14 Dwarakanath S, Lee AKC, DeLellis RA, et al. S100 protein positivity in breast carcinomas: A potential pitfall in diagnostic immunohistochemistry. Hum Pathol 1987;18:1144-1148.

15 Stroup RM, Pinkus GS. S100 immunoreactivity in primary and metastatic carcinoma of the breast: a potential source of error in immunodiagnosis. Hum Pathol 1988;19:949-953.

16 Gillett CE, Bobrow LG, Millis RR. S100 protein in human mammary tissue-immunoreactivity in breast carcinoma, including Paget's disease of the nipple, and value as a marker of myoepithelial cells. J Pathol 1990;160:19-24.

17 Thorner PS, Kahn HJ, Baumal R, et al. Malignant myoepithelioma of the breast. An immunohistochemical study by light and electron microscopy. Cancer 1986;57:745-750.

18 Tavassoli FA. Myoepithelial lesions of the breast. Myoepitheliosis, adenomyoepithelioma, and myoepithelial carcinoma. Am J Surg Pathol 1991;15:554-568.

19 Lakhani SR, O’Hare MJ, Monaghan P, et al. Malignant myoepithelioma (myoepithelial carcinoma) of the breast: a detailed cytokeratin study. J Clin Pathol 1995;48:164-167.

20 Cartagena Jr N, Cabello-Inchausti B, Willis I, et al. Clear cell myoepithelial neoplasm of the breast. Hum Pathol 1988;19:1239-1243.

21 Kuwabara H, Uda H. Clear cell mammary malignant myoepithelioma with abundant glycogen. J Clin Pathol 1997;50:700-702.

22 Jones C, Foschini MP, Chaggar R, et al. Comparative genomic hybridization analysis of myoepithelial carcinoma of the breast. Lab Invest 2000;80:831-836.

23 Rosen PP. Adenomyoepithelioma of the breast. Am J Surg Pathol 1987;18:1232-1237.

24 Young RH, Clement PB. Adenomyoepithelioma of the breast. A report of three cases and review of the literature. Am J Clin Pathol 1988;89:308-314.

25 Saez A, Serrano T, Azpeitia D, et al. Adenomyoepithelioma of the breast. A report of two cases. Arch Pathol Lab Med 1992;116:36-38.
26 Koyama M, Kurotaki H, Yagihashi N, et al. Immunohistochemical assessment of proliferative activity in mammary adenomyoepithelioma. Histopathology 1997;31:134-139.

27 Trojani M, Guiu M, Trouette $\mathrm{H}$, et al. Malignant adenomyoepithelioma of the breast. An immunohistochemical, cytophotometric, and ultrastructural study of a case with lung metastases. Am J Clin Pathol 1992;98:598-602.

28 Simpson RHW, Cope N, Skalova A, et al. Malignant adenomyoepithelioma of the breast with mixed osteogenic, spindle cell, and carcinomatous differentiation. Am J Surg Pathol 1998;22:631-636.

29 Ahmed AA, Heller DS. Malignant adenomyoepithelioma of the breast with malignant proliferation of epithelial and myoepithelial elements. A case report and review of the literature. Arch Pathol Lab Med 2000;124:632-636.

30 Trendell-Smith NJ, Peston D, Shousha S. Adenoid cystic carcinoma of the breast: a tumour commonly devoid of oestrogen receptors and related proteins. Histopathology 1999;35:241-248.

31 Damiani S, Riccioni L, Pasquinelli G, et al. Poorly differentiated myoepithelial cell rich carcinoma of the breast. Histopathology 1997;30:542-548.

32 Tsuda H, Takarabe T, Hasegawa T, et al. Myoepithelial differentiation in high-grade invasive ductal carcinoma with large central acellular zones. Hum Pathol 1999;30:1134-1139.

33 Tsuda H, Takarabe T, Hasegawa F, et al. Large, central acellular zones indicating myoepithelial tumour differentiation in high-grade invasive ductal carcinomas as markers of predisposition to lung and brain metastases. Am J Surg Pathol 2000;24:197-202.

34 Jimenez RE, Wallis T, Visscher DW. Centrally necrotizing carcinomas of the breast. A distinct histologic subtype with aggessive clinical behavior. Am J Surg Pathol 2001;25:331-337.

35 Stingl J, Eaves CJ, Kuusk U, et al. Phenotypic and functional characterization in vitro of a multipotent epithelial cell present in the normal adult human breast. Differentiation 1998;63:201-213.

36 Stingl J, Eaves CJ, Zandieh I, et al. Characterization of bipotent mammary epithelial progenitor cells in normal adult human breast tissue. Breast Cancer Res Treat 2001;67:93-109.

37 Iwaya K, Ogawa H, Izumi M, et al. Stromal expression of CD10 in invasive breast carcinoma: a new predictor of clinical outcome. Virchos Arch 2002;440:589-593.

38 Chauhan H, Abraham A, Phillips JRA, et al. There is more than one kind of myofibroblast: analysis of CD34 expression in benign, in situ, and invasive breast lesions. J Clin Pathol 2003;56:271-276.

39 Barbareschi M, Pecciarini L, Cangi MG, et al. p63, a p53 homologue, is a selective nuclear marker of myoepithelial cells of the human breast. Am J Surg Pathol 2001;25:1054-1060. 